Regards sur l'économie allemande

Bulletin économique du CIRAC

98-99 | 2010

Varia

\title{
Politique budgétaire : sortie de crise dès 2011
}

Isabelle Bourgeois

\section{CpenEdition}

\section{Journals}

Édition électronique

URL : https://journals.openedition.org/rea/4195

DOI : 10.4000/rea.4195

ISBN : 978-2-8218-0892-8

ISSN : 1965-0787

Éditeur

CIRAC

Édition imprimée

Date de publication : 26 octobre 2010

Pagination : 79

ISSN : 1156-8992

Référence électronique

Isabelle Bourgeois, "Politique budgétaire : sortie de crise dès 2011 », Regards sur l'économie allemande [En ligne], 98-99 | octobre 2010, mis en ligne le 05 novembre 2010, consulté le 28 juin 2022. URL : http://journals.openedition.org/rea/4195 ; DOI : https://doi.org/10.4000/rea.4195

Ce document a été généré automatiquement le 29 septembre 2020.

(C) CIRAC 


\title{
Politique budgétaire : sortie de crise dès 2011
}

\author{
Isabelle Bourgeois
}

En 2010, la croissance allemande est soutenue en partie par les mesures exceptionnelles adoptées dans le cadre de la crise financière mondiale pour soutenir la conjoncture. Dans leur rapport d'automne (14-10-2010), les Instituts de recherche économique chiffrent leur impact sur le déficit 2010 à $0,9 \%$ du PIB par rapport à 2009. Dans le cadre de la stratégie de sortie de crise, il ne sera plus que de 0,2 \% l'an prochain. Le plan de programmation budgétaire du gouvernement fédéral pour la période 2011/14, présenté le 7 juin dernier (voir REA 97/10), prévoit une réduction drastique des dépenses publiques. Les Instituts ont procédé à une estimation de l'impact de cette politique, dont voici les principaux éléments. (IB)

2010 et 2011 : impact des diverses mesures de politique budgétaire (variations par rapport à 2009, en milliards $€$ )

\begin{tabular}{|l|l|l|}
\hline & $\mathbf{2 0 1 0}$ & $\mathbf{2 0 1 1}$ \\
\hline \hline Mesures en vigueur jusqu'en septembre 2009 & & \\
\hline Suppression progressive de la prime d'accession à la propriété & 1,3 & 2,5 \\
\hline Amortissement progressif des biens mobiliers (mesure transitoire) & $-2,4$ & $-2,2$ \\
\hline Baisse des barèmes de l'IR & $-2,7$ & $-3,1$ \\
\hline Autres mesures fiscales (notamment en faveur des prestations artisanales) & $-0,8$ & $-1,1$ \\
\hline Hausse du seuil de dégrèvement des cotisations maladie et dépendance & $-7,1$ & $-8,7$ \\
\hline Hausse des allocations par enfant (et versement de la « prime » par enfant) & 1,9 & 2,0 \\
\hline
\end{tabular}




\begin{tabular}{|c|c|c|}
\hline Baisse du montant des cotisations à l'assurance maladie & $-2,4$ & $-2,6$ \\
\hline Hausse du montant des cotisations à l'assurance chômage & & 1,5 \\
\hline Soutien au chômage technique (remboursement des cotisations) & 0,1 & 1,3 \\
\hline Hausse de l'investissement public & $-5,0$ & $-5,0$ \\
\hline « Prime à la casse » & 3,4 & 4,2 \\
\hline Modification du mode de calcul des retraites & $-2,3$ & $-3,3$ \\
\hline Autres mesures de soutien & $-0,2$ & $-0,2$ \\
\hline Total & $-16,2$ & $-14,7$ \\
\hline $\begin{array}{l}\text { Mesures dans le cadre de la Loi Wachstumsbeschleunigungsgesetz (en vigueur depuis } \\
\text { le 01-01-2010) }\end{array}$ & & \\
\hline Hausse de l'allocation par enfant et du dégrèvement par enfant & $-4,3$ & $-4,5$ \\
\hline Réduction des impôts pesant sur les entreprises & $-0,7$ & $-2,2$ \\
\hline Autres mesures fiscales & $-1,1$ & $-1,5$ \\
\hline Total & $-6,1$ & $-8,2$ \\
\hline $\begin{array}{l}\text { Mesures de consolidation budgétaire du Bund (Zukunftspaket : « Paquet d'avenir ») } \\
\text { adoptées en juin } 2010\end{array}$ & & \\
\hline Création d'une taxe sur les transports aériens & & 1,0 \\
\hline Création d'un impôt sur les centrales nucléaires & & 2,3 \\
\hline Réduction des avantages fiscaux accordés en matière de taxes sur l'énergie & & 1,3 \\
\hline Modification du droit des dépôts de bilan & & 0,3 \\
\hline Obligation faite à Deutsche Bahn AG de payer des dividendes & & 0,5 \\
\hline Réduction de l'allocation parentale & & 0,7 \\
\hline $\begin{array}{l}\text { Suppression de l'allocation complémentaire transitoire versée aux chômeurs } \\
\text { passant sous le régime de l'ALG II }\end{array}$ & & 0,2 \\
\hline Suppression de la composante « chauffage » de l'allocation logement & & 0,1 \\
\hline Modifications des dispositions des chapitres II et III du Code social (SGB II et SGB III) & & 2,0 \\
\hline Economies réalisées au niveau des dépenses non affectées & & 1,5 \\
\hline Baisse des dépenses administratives & & 0,8 \\
\hline
\end{tabular}




\begin{tabular}{|l|l|l|}
\hline Report de la reconstruction du château Stadtschloss à Berlin & & 0,1 \\
\hline Total & & $\mathbf{1 0 , 8}$ \\
\hline Autres mesures & & \\
\hline $\begin{array}{l}\text { Prélèvement de cotisations complémentaires par certaines caisses d'assurance } \\
\text { maladie }\end{array}$ & 0,7 & 0,0 \\
\hline \hline Economies dans le secteur de la santé & & 3,5 \\
\hline \hline Hausse du montant des cotisations à l'assurance maladie légale & 0,0 & 5,2 \\
\hline Hausse du montant du forfait de base versé au titre de l'ALG II (« Hartz IV ») & $\mathbf{0 , 0}$ & $-\mathbf{0 , 5}$ \\
\hline Création de la «Carte à puce Education » (Bildungs-Chipkarte) & & $-0,6$ \\
\hline Total & $\mathbf{0 , 7}$ & $\mathbf{7 , 6}$ \\
\hline Total (budget) & $\mathbf{- 2 1 , 6}$ & $\mathbf{- 4 , 5}$ \\
\hline Total (impact sur le déficit en \% du PIB) & $\mathbf{- 0 , 9} \%$ & $\mathbf{- 0 , 2} \%$ \\
\hline
\end{tabular}

Source : Gemeinschaftsdiagnose Herbst 2019. Deutschland im Aufschwung - Wirtschaftspolitik vor wichtigen Entscheidungen (14-10-2010) / BMF ; calculs des Instituts.

\section{INDEX}

Mots-clés : budget, finances publiques, politique économique, politique budgétaire, croissance, conjoncture, crise 